\title{
A 'home-international' comparative analysis of widening participation in UK higher education
}

\author{
Michael Donnelly ${ }^{1} \cdot$ Ceryn Evans $^{2}$
}

Published online: 28 March 2018

(C) The Author(s) 2018

\begin{abstract}
Since devolution of education policy to the four 'home' nations of the UK, distinct approaches to addressing social inequalities in higher education participation have developed across the four jurisdictions (England, Wales, Scotland and Northern Ireland). From a critical examination of 12 policy documents, this paper presents a comparative policy analysis of the qualitatively distinct ways that inequalities in higher education are conceptualised across the home nations. Basil Bernstein's theoretical ideas are drawn on to help unearth distinctions in their beliefs about the underlying nature of educational inequalities. These can be understood in relation to their degree of closeness to either neoliberal or social democratic ideological positions, and we show that the home nations of the UK place differing emphases on what form of higher education they aim to widen access to, and how they intend to achieve this.
\end{abstract}

Keywords 'Home-international' comparative research · Widening participation · Higher education policy $\cdot$ Basil Bernstein

\section{Introduction}

Despite the 'massification' of Higher Education (HE) in recent decades, patterns of participation have remained deeply uneven across the UK (Blanden and Machin 2004; Chowdry et al. 2013). Those from lower socioeconomic groups are most likely to be under-represented in HE (Harrison and Hatt 2010; Harrison 2011), and children eligible for Free School Meals (FSM) (a proxy indicator of socioeconomic disadvantage), are amongst the least likely to enter $\mathrm{HE}$ at aged 18-19 (Chowdry et al. 2013). Widening participation in HE has therefore been high on

Michael Donnelly

m.p.donnelly@bath.ac.uk

Ceryn Evans

evansc15@cardiff.ac.uk

1 Department of Education, University of Bath, Bath, UK

2 School of Social Sciences, Cardiff University, Cardiff, UK 
the agenda of UK governments in recent decades, aligned with wider social justice and economic development concerns (Adnett and Tlupova 2008; Harrison and Hatt, 2010) and more recently, with policy debates about social mobility in the UK (Department for Business, Innovation and Skills, 2011; 2016; Welsh Government 2013). Across the four 'home' nations of the UK, a plethora of policies and initiatives have been developed in order to address inequitable rates of participation in $\mathrm{HE}$, essentially by widening participation in $\mathrm{HE}$ amongst those most socioeconomically disadvantaged.

Prior to the devolution of major areas of public policy in 1998, higher education across the UK was ostensibly centrally controlled by the national UK Government in London (although centralised decisions were administered through Government offices in each of the four jurisdictions of the UK-England, Wales, Northern Ireland (NI) and Scotland-which had differing degrees of influence on their particular application over time). Historically, then, it is true to say that differences between the four jurisdictions of the UK were apparent even before formal devolution of powers occurred. Scotland in particular has historically developed distinctive forms of provision, which remain today, including the 4-year degree, whilst generally Welsh and Northern Irish policy was more aligned with English provision (Keating 2005). Following parliamentary devolution of formal powers in the UK in 1998, legislative powers over education and training were devolved across the four jurisdictions of the UK, albeit, quite unevenly between them (Keating 2002; Jeffry 2006). Since then, policies and agendas for widening participation produced by each of the four home nations have been characterised by both divergences as well as convergences (Gallacher and Raffe 2011). A significant area of divergence has been in HE funding arrangements and systems of student financial support adopted by each of the home nations (Gallacher and Raffe 2011; Raffe, 2013). These divergences have led to distinct approaches to widening participation and the formation of nuanced mechanisms for supporting entry to HE amongst students from low-income backgrounds Gallacher and Raffe (2011). One of the most striking differences between the home nations is in their tuition fee arrangements. Scottish domiciled students have not been required to pay HE tuition fees unlike those in other parts of the UK (however, a very recent policy change means that from 2017 Scottish domiciled students pay up to $£ 9000$ if they study outside of Scotland). In Northern Ireland and Wales, home students (i.e. Northern Irish and Welsh-domiciled students) pay no more than the base rate (set at approximately $£ 4000$ ) if they study HE within their home nation whilst England-domiciled students pay up to $9000 \mathrm{a}$ year, wherever they study in the UK. Reflecting these differences are nuances in the way HE institutions (HEIs) within the home nations are monitored in terms of their performance on widening participation and access. In England, in 2016/17, HEIs are required to submit 'Access Agreements' to the Office for Fair Access (OFFA), stating their intended investment in financial support (i.e. bursaries and grants) for students from low-income backgrounds. Similarly, in Wales, HEIs have been required to submit Fee Plans to the HE Funding Council for Wales (HEFCW) stating how they would invest a proportion of their fee income in supporting equality of opportunity in access to HE (Higher Education Funding Council for Wales, 2011; 2013). ${ }^{1}$ In NI, HEIs had to submit Access Agreements to OFFA until 2013 but since then have had to report to the Department for Employment and Learning in NI. In

\footnotetext{
${ }^{1}$ Fee Plans have been a statutory requirements of HEIs in Wales since 2012/2013 when HEIs could charge up to 9000 a year in tuition. Fee Plans were renamed 'Fee and Access Plans' under the 2015 HE Act reflecting the Welsh Government's changes to particular element of the plans, namely, the renewed emphasis on 'equality of opportunity in connection with access to HE'
} 
Scotland, HEIs and colleges have to report to the Scottish Funding Council through submitting

'Outcome Agreements' which state commitments to widening participation and access.

Distinctions are also observable in the structure and form of $\mathrm{HE}$ in each of the home nations, which are historically grounded. England has the largest number of HEIs and students, followed by Scotland and then Wales, with very few institutions in Northern Ireland. England also has most of the institutions that are members of the Russell Group of research-intensive HEIs, whilst Scotland has a longer and more established tradition of HE being offered through Further Education. Wales currently has eight universities, plus the Open University ${ }^{2}$ in Wales, with only one of its universities being a member of the Russell Group Devolution of HE policy to the home nations which has also brought about the development of varied packages and arrangements for student financial support - which differ both in the level of support and whether this is provided as a repayable loan or non-repayable grant. In Scotland, for example, the maximum amount provided is $£ 7625$ (for the lowest-earning households) with part of this money being offered as a non-repayable grant. This is a similar amount provided to English students (albeit as a repayable loan only). In contrast, Wales provides a more generous amount of up to $£ 9000$ (for the lowest-earning households) - the vast majority (£8100) of which is given as a non-repayable grant. Northern Ireland's provision is similar to Wales, although not as generous (a maximum of $£ 4039$ for students who study in Northern Ireland, and up to $£ 9250$ for those studying elsewhere in the UK), and only around a third of this maximum amount is provided as a non-repayable grant.

There have also been distinctions between the home nations in their rates of participation in $\mathrm{HE}$ in general as well as rates of participation amongst men, women and students from various socioeconomic groups. Historically, Scotland has enjoyed higher rates of HE participation than England and Wales, and higher proportions of working-class students have entered HE in Scotland than in England or Wales (Lannelli 2007). Yet, social inequalities in rates of participation in Scotland are more striking here than they are in England and Wales (Iannelli 2007). Patterns of participation in HE amongst students traditionally under-represented in HE have not, therefore, been even across the home nations, nor have the financial arrangements designed to support participation in HE amongst these groups.

Within this diverse UK policy context, there has been little attempt to examine understandings about the nature of (socioeconomic and educational) inequalities (both in terms of their causes and how they might be addressed) that are inherent within the different policies adopted across the home nations. From a 'home-international' comparative perspective, the major contribution of this paper is therefore to critically examine divergences (as well as points of convergence) between the home nations in their conceptualisations of equality on which their widening participation policies rest. A critical examination of 12 key policy documents reveals qualitatively distinct conceptualisations of equality giving rise to subtly different emphases within widening participation policy texts.

\section{'Home-international' comparative research}

International comparative analyses have had a particularly significant and lengthy history both in sociological research and within UK policymaking (Felstead et al. 1994; Raffe 1998). More

\footnotetext{
${ }^{2}$ The Open University is a HEI which has a 'base' institution in each of the home nations. It is a distance learning and research university which offers flexible and part-time higher education and has a distinct admissions policy from all other HEIs in the UK.
} 
contemporary research has, however, been characterised by a growing interest in home-international comparisons, as a more useful lens of policy learning (Delamont and Rees 1997; Raffe 1998, 2013). Home-international comparisons (i.e. between England, Scotland, Wales and Northern Ireland) are relatively technically and conceptually simpler than overseas comparisons because of their broadly similar education sectors, stages and structures (Raffe 1998). The home nations also share similarities in their social and economic contexts, which means that these contexts can be held more or less constant when comparisons are made (Raffe 1998).

However, home-international comparisons have not been without their problems (Raffe 1998; Rees 2005). Indeed, represented within the media and academic commentaries, these kinds of comparisons have routinely suffered from 'English-centrism' in which the education policies and provision of other home nations are either rendered invisible or compared (often unfavourably) from the vantage point of English ones (Power 2016). There has been very little (with the exception of important work by Raffe 2013; Gallacher and Raffe 2011), detailed UK intranational comparative policy analysis of the distinct approaches to education policy that have developed over time. Indeed, much of the policy analysis literature tends to focus on analysis of one home nation or a comparison of just two of them (such as Welsh and English policies (Rees 2005). Here, we compare and contrast all four jurisdictions in their underlying assumptions about the nature of educational inequalities which are manifest in their policies on widening participation in HE. The different conceptualisations and policy choices adopted across the home nations have potentially important consequences for the structure of $\mathrm{HE}$ and patterns of participation within it, and are deserving of a more close-up comparative analysis.

\section{Methods}

Contemporary HE policy documents from each of the four home nations were examined according to their underlying assumptions about the nature of educational inequalities (their causes, and approaches to addressing them). In recent years, the home nations have produced a plethora of policy texts on HE. We selected 12 of these on the grounds that they best represent each of the home nations' most recent and substantial policies and agendas in relation to HE generally, as well as widening participation and access specifically. They therefore provided prime opportunity for examining conceptualisations of equality within them. These texts did, however, range in their purpose, content and intended readership. They included the most recent HE policy text, or in some cases, the one immediately preceding it (these usually set out the particular Government's HE policy strategy in general, or its policies in relation to widening participation/access specifically). This was slightly different for Scotland because at the time the research was conducted, no publicly available policy text which sets out Scotland's vision for HE specifically was available. For Scotland, therefore, we examined a policy document that set out the Scottish Government's vision for Scotland more generally, rather than $\mathrm{HE}$ specifically, though $\mathrm{HE}$ and issues of equality were pertinent themes in this text. In addition, policy documents produced by funding councils in each of the jurisdictions were also examined (where they were publicly available), and these typically set out the funding council's approach or plan for widening participation in HE. The 12 documents drawn on in our analyses are listed in Appendix Table 1.

An inductive thematic analysis was conducted on the documents, guided by the following exploratory questions: How do each of the home nations conceptualise the underlying nature 
of inequalities in HE participation? Are subtle distinctions in their assumptions and understandings apparent from their policy texts? To what extent do their emphases reflect orientations towards social democratic values (associated with equality of outcome) or liberal democratic (and neoliberal) values aligned with equality of opportunity? Analysis involved attaching codes derived from the documents as well as the wider literature on widening participation to sections of data in the documents. Codes were categorised according to connections, links and consistencies between them in order to identify themes in the data.

Undertaking a home-international comparison of HE systems and polices presents a number of challenges, not least because the HE systems at the centre of such an analysis are routinely uneven in terms of their size and scale. In our comparison, Wales and NI had just nine and three universities respectively, Scotland had 19 and England had 109 HEIs. There were also differences in the scope of HE bodies and organisations in each home nation; for example, NI did not have a HE Funding Council that was quasi separate from Government, whilst the other home nations did. These variations are important as they inform the role of HE in each jurisdiction in addressing social and economic policy goals, and this is reflected in variations in the scope and number of policy texts dedicated to widening participation in HE. Notwithstanding these variations, the conclusions we draw here are important as they deepen our understanding about the conceptualisations of equality underpinning widening participation policies in each of the home nations.

\section{Conceptualising 'widening participation'}

The doctrines of social and liberal democracy are both complex and varied, with long histories and a range of expressions in politics and governance across the globe. However, broadly stated, as doctrines they are quite distinct in terms of their conceptions of equality. Whilst social democracy has historical orientations towards equality of outcome, liberal democratic values are wedded more strongly to the idea of equality of opportunity. Liberal democracy is closely aligned to neoliberalism which accepts inequality (indeed, may even actively endorse it; Giddens 1998) on the grounds that unequal outcomes are the just and fair consequence of individual effort and hard work (its deleterious effects softened in the UK by the presence of a placatory welfare state). A liberal democratic ideology thus champions equality of opportunity and regards it as a desirable necessity since it provides all people with what is perceived as 'the same' opportunity to excel and reach positions of prestige, according to their individual merits. By contrast, in a social democracy, removing obstacles at the outset (inequalities in opportunity) is not sufficient to achieve equality of outcomes (Rothblatt 2007). Social democratic ideology is therefore more strongly concerned with the concept of equality of outcome, and seeks egalitarian educational systems.

The sociology of education provides a language of description to understand distinct viewpoints about the nature and causes of inequality circulating across the home nations, and Basil Bernstein's $(1975,1996)$ work in particular is drawn upon here. Bernstein's theoretical endeavour was aimed at bringing a sharper theoretical grasp of educational institutions and pedagogy, and the ways in which these may be differently aligned to the pupils (and their families) they serve. He showed how the nature of pedagogies and institutions can themselves create different levels of engagement, dependent upon the extent to which families understand them and agree with the ends they promote. Central to his theorisation are the 'instrumental' and 'expressive' orders; these define, on the one hand, the sorts of 
knowledge transmitted (instrumental), and on the other the images of conduct, character and manner (expressive) students are expected to display and embrace. A family may agree with the end goals of these orders (for example, to achieve high grades, and conform to certain modes of behaviour and conduct) but may be unable (or, indeed, unwilling because of a clash of home-school values) to help their child achieve them (i.e. not understand the means by which they are transmitted).

Bernstein's framework is useful in showing, theoretically at least, that there are potentially two dimensions to educational success or failure: (i) the culture of the educational institution and (ii) the culture of the family (Donnelly 2016). His work is helpful in deciphering the assumptions carried by policy texts about where attention needs to be directed in order to address educational inequalities, particularly in terms of access and participation in HE. It is likely that policymakers in each of the home nations of the UK will hold subtly different perspectives about the formation of educational inequalities, which can be gleaned from the way they craft their policy texts and from the kinds of discourses evident within them. The policy texts from each of the home nations analysed here are found to contain paradoxical messages about the nature of educational inequalities and where attention needs to be directed to address them.

One perspective gives primacy to the family, and assumes that it is their lack of understanding of what Bernstein refers to as the means of educational transmissions (or acceptance of their ends) which brings about educational inequalities. This conceives of educational inequalities as produced through what families may be 'lacking' and their mis-alignment with educational institutions. For example, the means of transmission could be in terms of displaying what the university regards as 'confidence', being able to present oneself in 'appropriate' ways within the application process, feeling entitled to take part in university study (all of which those with greater stores of cultural capital might have been socialised into from an early age). In relation to HE policy, this understanding about the nature of inequalities aligns more strongly with ideas of equality of opportunity since the emphasis is on abating apparent 'deficits' and opening up HE opportunities for groups of individuals under-represented in HE. Here, inequalities of outcome are less important if what are perceived of as obstacles to entry are removed. As we shall see, this understanding about the nature of inequalities is manifest in particular emphases on the role of the individual within widening participation agendas.

Other understandings on the nature of educational inequalities afford far greater weight to the HE system itself, and assume that inequalities exist because the end goals of HE and the means by which these are transmitted, in Bernstein's terms, are incorrectly aligned to the families and individuals they serve. Educational inequalities, as understood from this vantage point, derive from within the HE system itself, which is not serving in an equitable way all groups within society. It does not, for example, account for diverse ways of expressing oneself or different ways of conducting and behaving. In this sense, the underlying assumption here is that the HE system itself, as opposed to the groups it serves, needs to change. In relation to HE policy, this conception is aligned more strongly with the idea of equality of outcome whereby the emphasis is on creating more equitable outcomes for learners. This emphasis does not, however, necessarily aim for uniformity in the HE experience, or the end goals of HE for all learners. Rather, as we shall see, this orientation towards equality of outcome is manifest in an emphasis on changing the HE system to enable a diversity of learners to enter it.

These seemingly contradictory assumptions about the basis of educational inequalities can be found to differing degrees both within and across policy texts from the four nations of the 
UK. Whilst some Governments appear to lean more towards one perspective over the other, it is also the case that they inevitably contain a mixture of both. In what follows, the policy documents from each of the four home nations are interrogated according to their underlying assumptions about the nature of educational inequalities. We ask, where do the different home nations direct attention in their policymaking and what does this say about how they understand the underlying nature of inequalities? Does their policy approach reflect an approach orientated largely around equality of opportunity or equality of outcome?

\section{Constructing widening participation policy across the 'home' nations}

\section{England and Wales}

Historically, there is a mixture of continuity and divergence in English policy approaches to widening participation. Brooks (2013) highlights the continuity evident across New Labour and Coalition administrations, in terms of their identical understandings of young people as active consumers, evident across both school and university levels of education. Set within a strongly marketised educational field, the administrations emphasised the importance of choice as a key mechanism in driving quality of educational provision. The present Conservative UK Government has continued to endorse and extend further this approach. Their most recent White paper contains four key areas for policy development, which include introducing the teaching excellence framework (TEF), an emphasis on the growth of new providers and courses of study, encouraging developments in the transfer of credits between providers and courses, and greater transparency of information to facilitate improved student choice. The ability to transfer credits gained from institutions and courses is intended to be facilitated by more informed and active choosers who can use the information they have at their disposal to change their choices as and when necessary. Individuals are conceived of as proactive consumers in the sense that they are perceived of as continually seeking out courses and institutions that will return them higher rewards (framed in terms of graduate earnings and 'teaching quality').

Contemporary English policymaking is more strongly aligned to equality of opportunity in its approach, with a concerted emphasis on active consumerism, choice within a diverse education market and availability of information. Extending the availability of information and knowledge to build capacity for making more 'informed' choices is a central tenet of their approach. In contrast to other home nations (especially Wales, as we shall see later), English policy appears less orientated around equalising people's starting points, and more focused on ensuring that there is equal access to information and educational opportunities. From a Bernsteinian perspective, there is an emphasis on increasing the individual's understanding of the education system (and universities in particular) as it stands, such as what is valued by the system, how to 'succeed' educationally, and ways of presenting oneself as 'legitimate' within the context. Outreach work, delivered by HEIs themselves, is often based around principles of increasing young people's capacity to enter HE, including their levels of attainment, knowledge and 'aspirations' for university-level study. The English Government's roach is also about helping excluded groups to accept the end goals of HE study (such as graduate employment), in terms of persuading them of the so-called benefits of studying for a degree (as defined by the HE system itself).

An orientation towards equality of opportunity celebrates choice, as a central mechanism for marketising HE (Olssen and Peters 2005). It also ratifies a stratified HE system because this 
putatively propels competition and choice, the dual tenets of a market system of HE. This is made clear in the policy documents of the English government which construct the HE system as deeply (but properly) hierarchical.

The most disadvantaged young people are seven times less likely than the most advantaged to attend the most selective institutions. This is not good enough. Individuals with the highest academic potential should have a route into $H E$, and the most selective institutions in particular

Department for Business, Innovation and Skills (2011), pp. 6-7

Here, neoliberal ideas have clearly permeated English HE policymaking. Through an emphasis on improving 'access' to, and 'success' within, a hierarchically stratified HE system, England not only takes for granted the deeply unequal HE system but also actively endorses and approves it. ${ }^{3}$ The greater emphases on highly selective HEIs in the English Government's HE policy texts, in comparison to texts from the three other home nations, reflect nuances in the way in which HE is conceived of in relation to social mobility. For the English government, HE, and highly selective HEIs in particular, is synonymous with social mobility.

This narrative of changing the student is expressed even more strongly in the English funding council's policy document (HEFCE 2011). The funding council's overall 'strategic response' to widening access has seven key elements (HEFCE 2011, pp. 43-44) all of which are about initiating change at the student level, with only one mention of changing the institution, which relates to HEIs creating more options for part-time study. Part-time study is to some extent about adapting the HE system to fit a broader reach of society, but it is not about fundamentally changing the end goals of HE study, or the means by which these are achieved.

Whilst the UK Government's orientation is more directed towards enabling individuals to fit into the HE system as it stands, it is clear that there is still at least some attempt to initiate change at the institutional level. This is evident in their criticism of the standard 3-year model of degree-level study and their attempt to introduce 2-year degree programmes as well as other adaptations including degree apprenticeships, flexible study options and an emphasis on transfer of credits. At the same time, these institutional adaptations are set within the broader narrative of 'student choice' and a HE 'market' that is hierarchical and segmented in nature.

In contrast to England, Wales appears to lean more strongly towards social democratic notions of equality of outcome. This alignment with notions of equality of outcome is reflected in a number of key policy agendas which the Welsh Government has appropriated in relation to widening access to $\mathrm{HE}$ in recent decades. In particular, the Welsh Government has maintained a significant emphasis on collaboration with the FE sector in the delivery of HE in general and in addressing widening access agendas specifically (embodied most prominently in the Universities of the Heads of the Valley's Initiative (discussed below)). The Welsh Government also makes stronger claims to creating a more inclusive and diverse HE system, both in terms of the levels and modes of delivery, as well as its student body. This is reflected in the emphasis on 'maximising participation' through different ways of experiencing HE, including part-time study, work-based study and HE delivered within the FE sector and on

\footnotetext{
${ }^{3}$ Boliver 2006. Discusses the social class differentiation in participation in different types of HE (namely, different types of HEIs, including 'research-intensive' and post-1992 universities) in the UK
} 
different levels of HE (including Foundation Degrees and Higher Apprenticeships). Its policy texts articulate a narrative of 'flexible' HE provision and flexible ways of experiencing HE:

We will support demand-led flexible learning opportunities in regions and communities...opportunities must be relevant, tailor made and fit around work and lifestyle commitments

Higher Education Funding Council for Wales (2011), p.10

In this narrative, the HE landscape is constructed as an arena which is not only made up of a diversity of modes of study, but also of types of learner. In this way, Welsh Government's widening access to HE policy is coherent with notions of equality of outcome; HE is viewed as providing individuals with opportunities to gain access to employment and life opportunities, but the HE experiences which lead to these opportunities may be varied and diverse. They include different modes and levels of $\mathrm{HE}$ and forms of delivery (including through community settings and the FE sector), catering for the diverse needs of the society it serves.

HE providers should look to provide an appropriate offer to people at all stages of life through a variety of programmes, and through a flexible and dynamic delivery system that meets students' expectations and needs. The aim should be to widen access to all, including those living in rural areas of Wales, rather than opening up access only to a few. Wales needs a blend of full- and part-time provision at varying levels, including continuing professional development, and focused on employer requirements.

Higher Education Funding Council for Wales (2011), p. 17

Underlying the Welsh approach to widening participation is an assumption that inequalities in participation arise when the education system as it stands is not aligning itself appropriately to all groups in society. This is a subtly different vantage point from that taken in England. Wales' more concerted emphasis in its policy texts on 'flexible ways of experiencing HE' including 'shorter accredited programmes, which are better tailored to fit around people's lifestyles and responsibilities' (Welsh Assembly Government, 2009, p. 12), reflect its orientations towards notions of equality of outcome, in which different forms of HE play a pertinent role in promoting equality.

The University of the Heads of the Valley's Initiative (UHOVI) is perhaps the most pertinent example of this egalitarian orientation towards equality of outcome. UHOVI is a Welsh Government-supported programme, delivered by the University of South Wales, which aims to provide HE-level courses and programmes to people living in and around (some of the most economically disadvantaged) localities of the South Wales valleys in local contexts and venues. This programme is intended to provide people opportunities to experience HE in order to gain skills needed for personal development and employment within the local community in which they live and work. Indeed, many of the courses and programmes delivered through UHOVI are part-time, pre-degree level and delivered through community locations and FE colleges. Underlying this policy is an assumption that inequitable rates of participation in $\mathrm{HE}$ derive from a HE system which excludes groups through their lack of understanding of the means of educational transmission. It is sensitive to the fact that some groups may not have performed well or engaged with their learning at school because they were either not equipped with an understanding of the processes involved in learning and schooling or, indeed, not inclined to accept its (middle class) values. 
Whilst all four home nations made reference to flexible provision of some kind, including different modes of study (i.e. part-time) and different levels (including pre-degree level such as Foundation degrees), they figure most strongly in Welsh documents. In Bernstein's terms, this policy position is underpinned by an assumption that educational inequalities arise when education systems do not (because of their values and structures) enable access by all sections of society. In his view, a large section of the population (essentially from amongst the 'working classes') do not understand the means or accept the ends of HE as it is currently structured, inhibiting their ability to engage. Thus, in Wales, the attempt seems to be more about aligning the HE system more closely to a diversity of potential learners, with diverse needs.

Whilst the Welsh approach appears most consistent with the notion of equality of outcome, the principles of equality of opportunity have, nonetheless, at least partly seeped into Welsh policymaking over time. The Welsh Government's 2009 HE strategy ('For Our Future') makes no reference to 'social mobility', whilst its 2013 HE Strategy places greater emphasis on this, stating that 'widening access initiatives need to increase social mobility and contribute to tackling poverty' (Welsh Government 2013). In line with neoliberal value orientations, this policymaking regards $\mathrm{HE}$ as a key mechanism for social mobility in intergenerational terms (movement into privileged, middle-class lifestyles and employment). The presence of such neoliberal policy emphases reflects the significance of policies and discourses emanating from England on HE systems across the UK more widely, including the growing prominence of market-orientated policies within HE.

\section{Scotland and Northern Ireland}

Whilst England was more strongly orientated towards equality of opportunity in its policymaking, and Wales leaning closer to equality of outcome in its approach, Scotland and NI appeared to sit between these poles. There is not the same emphais placed on one orientation over the other as evident in England and Wales. Underlying Scottish and Northern Irish policymaking is an orientation around equality of opportunity (for example, programmes to raise aspirations and attainment) as well as outcome (for example, a move towards contextualised admissions in Scotland), with no single doctrine dominating.

Articulation pathways, defined as the college-based routes into university (students often transferring directly into their second/third year of university using credits obtained from college) have been a long-standing feature of Scottish approaches to widening participation. They can be interpreted as a means of recognising the value of knowledge gained from the Further Education sector and so a widened view of what counts as an appropriate student in HE (in terms of the kinds of knowledge they possess). At the same time, whilst this widened view of the educated student is socially democratic in one sense, it does little to change the privileging of certain kinds of curricular and pedagogy in HE which may be different from that experienced in Further Education. That said, the recommendation to grow articulation pathways (Scottish Government 2016) is being implemented by the Scottish Government, as evident from their implementation plan (Scottish Government 2017). There is action being taken to grow the number of articulation paths available across a more diverse range of HE courses and institutions. In encouraging the further expansion of articulation across a broader range of universities, it is clear that to some extent the Scottish Government views inequalities as deriving from an instrumental order which does not take account of diversity in prior learning 
experiences. To some degree, then, an orientation towards equality of outcome can be seen in Scottish policymaking, albeit within a highly stratified HE system.

In Scotland, an orientation towards equality of outcome can also to some extent be seen in the way the policy texts we analysed raise concern that more advantaged groups may be better positioned to display the kinds of non-academic dispositions that universities privilege, and therefore have a better chance of gaining acceptance to study at university. Scotland's HE funding council also makes reference to the use of contextualised admissions by HEIs as means of promoting a more equitable entry to HE. Underlying this is a belief that knowledge about the expressive order of the HE system, its image of appropriate conduct, character and manner, is held disproportionately by different groups in society. It is not the individual who is lacking, but the institution (or pedagogy), which is representative of only a narrow section of the population, disadvantaging others in the process. From this viewpoint, the institution needs to adapt and change to recognise a wider view of what counts as 'talent'; i.e. images of conduct, character and manner.

It may be argued that access thresholds are unfair and that everyone should be expected to meet the same academic standards. This would only be a good argument if all applicants had the same opportunities to realise their potential. But this is plainly not the case: disadvantaged learners face educational, cultural and systemic barriers which make their journey into HE much more difficult. It is therefore squarely upon their shoulders that any disadvantage or unfair denial of opportunity rests. Access thresholds will simply help correct this imbalance by creating a more level playing field until such time as fair access is achieved

Scottish Government 2016, p. 37

'Access thresholds' are an attempt to introduce contextualised admission in a more concrete way and involve lowering the entrance requirements for those considered to be excluded from HE. 'Threshold' refers to what are considered the minimum standards of achievement required to successfully undertake a degree course (i.e. to try to combat the inflated grades often demanded by high-status institutions brought about through competition for places). Implicit here is an understanding that individuals from different social groups will not equally hold (sufficient or 'correct') knowledge about the processes involved in acquiring knowledge at the school level. In other words, not all social groups start on an equal footing when they begin their schooling. As such, contextualised admission policies advocate change on the part of the institution (in the form of reduced 'offers' to applicants) to take into account this discrepancy within society, rather than requiring the individual to change through, for example, improving their own attainment level. To some extent then, this perspective assumes that it is the HE system itself that is misaligned with (all sections of) the society that it serves, and as such, it is the HE system which needs to adjust and adapt. However, since contextualised admission policies are overwhelmingly used by high-ranking HEIs to 'widen participation' in a conventional HE experience (typically, full-time, undergraduate degree courses, requiring high entry requirements), they remain preoccupied with widening participation in a conventional HE experience. The use of contextualised admission policies by individual HEIs thus absolves government of any responsibly to instigate change in the way HE is delivered at an institutional level. In this sense, contextualised admission policies address Bernstein's (1975) instrumental dimensions of HE (i.e. entry requirements, qualifications offered, etc.) but with little or no mention of its expressive dimensions, images of 
conduct, character and manner, transmitted by and required within HE. Contextualised admissions also do little to disrupt the hierarchical nature of HE provision in the Scottish system.

In common with Scotland, NI encompasses orientations towards both equality of opportunity and outcome in its approach to widening access. Its alignment with the former is illustrated in its funding arrangements and systems of student support and, associated with these, the requirements it has placed on HEIs to promote widening participation in light of increasing tuition fees. Following the introduction of new tuition fees arrangements in 2006, the NI Government proposed that HEIs wishing to increase their tuition fees to above the base level must produce Access Agreements (much like in England) which describe how the additional income would be invested in activities that promote widening participation in HE. The most recent funding arrangements (for students entering university in 2017/18) adhered to this underpinning principle, through ensuring that students living in NI and studying in NI do not pay more than $£ 4030$ in tuition. This orientation towards equality of opportunity is also illustrated in both Scotland and NI's emphasis on the provision of programmes designed to raise aspirations and/or attainment, targeted at the groups who are perceived as 'missing' the 'right' kind of knowledge, values and expectations. These programmes are regarded as playing a central role in widening participation in HE, as we see in both Scotland and NI's policy texts:

The department will seek to expand the range of aspiration and attainment raising programmes at school, college, community and the workplace

Department for Employment and Learning (2012), p. 29

Over the period of this plan, we will therefore give priority to widening access and improving attainment for young people from communities that are underrepresented in education

Scottish Funding Council (2015), p. 11

The emphasis on raising aspirations and attainment is predicated on the notion that this will provide excluded groups with the means (high aspirations and attainment) to participate in a conventional HE experience (namely, undergraduate study delivered by a university). Running throughout the Scottish Government's (2017) implementation plan is an overt emphasis on identification of those missing the most appropriate kinds of knowledge, attainment and aspirations as well as developing the most effective solutions to fill these gaps. It addresses the pro-valuable 'most disadvantaged' right. There is evidence of an attempt to improve the scientific rigour of mechanisms for identifying those in most 'need' of support, finding out more systematically and comprehensively who is in need. Aligned with this is a drive to create a sophisticated knowledge base about what specific interventions generate the best returns in terms of increasing levels of attainment, knowledge and aspirations. This mirrors the 'what works' agenda in wider public policy that has taken off so strongly in England. An orientation towards 'empowering' individuals (through raising their aspirations, attainment or both) to become more informed 'choosers' is evidence of a neoliberal approach that can increasingly be found in wider Scottish education policy, 
for example, its embrace of the OECD's PISA testing at the school level (Lingard and Sellar 2014). It is therefore difficult to argue that Scotland's policy emphases are entirely socially democratic in orientation.

Adherence to the principles of equality of opportunity, manifest in emphasis on raising attainment or aspirations to participate in HE, (akin to the English approach) is particularly evident in NI's policy texts:

To be successful in achieving higher level qualifications, people need to possess a number of characteristics. These include the aspiration to improve their educational level, confidence in their ability to do so, and the drive and determination to succeed in $H E$. An individual's aspirations, and their ability to realise those aspirations, are usually determined at a very early stage in their life

Department for Employment and Learning (2012), p. 24

Drive, determination and confidence are, of course, social constructs normalised here in an unproblematic way within the policy texts. They are aspects of what Bernstein (1975) refers to as the institution's expressive order, its images of conduct, character and manner. Evidently, the drive, determination and confidence referred to above are those 'qualities' which the NI HE system considers essential features of a person suited to HE. However, the version of confidence (or drive and determination for that matter) valued by the HE system is not necessarily going to be the version held or equally valued by all groups in society. Advocating that excluded groups need to engage in this kind of character training and develop these attributes of conduct, character and manner (Bernstein 1975, 1996) implicitly normalises extant means of educational transmission. In other words, to engage and succeed in HE individuals are presumed to need to understand how to act, behave and operate 'appropriately', according to attributes which are valued in HE and represent a 'legitimate' student identity. An attempt to align the individual with the HE system in its current form is also evident in terms of the end goals of HE study. The aspirations mentioned above to attend university assume a commitment to the end goals that universities value themselves (not necessarily those valued by all groups within society).

However, there are important distinctions between the emphases in Scotland and Northern Ireland's HE policy texts and those of England. In common with Scotland and Wales, the NI Government does not conceive of the HE system as uniform, but rather, composed of different modes and levels of HE, associated with varied employment and life opportunities. As such, widening participation is not concerned with widening participation in uniform HE opportunities and experiences, but to varied levels and modes of study, each associated with varied employment opportunities. This is illustrated most vividly in the substantial emphasis placed on the need for the growth and development of Foundations Degrees in Northern Irish policy documents.

Unleashing the talent and expertise of this workforce means that HE institutions must be more innovative in their provision and conscious of learner requirements. Such innovation must consider alternative forms of progression including advanced apprenticeships, Foundation Degrees and other professional and technical HE programmes within a credit based flexible framework

Department for Employment and Learning (2012), p. 31 
Implicit in this narrative is an understanding that educational inequalities often arise from institutional properties themselves that are misaligned with the broad society they serve, as seen in the cases of Welsh policymaking, and in accordance with an equality of outcome perspective. Thus, both Scotland and NI exhibit some attempt to adapt and modify aspects of the HE system itself with a view to aligning it to a more diverse society. In this sense, both countries' approaches to widening participation embody elements of equality of opportunity (for example, through their financial support arrangements) as well as more social democratic and egalitarian values which celebrate a diverse HE system encompassing varying modes and levels of study.

\section{Discussion and conclusions}

Across and within each of the four UK home nations, diversity exists in policy development aimed at addressing social inequalities in HE participation. We have shown that what underlies each of these distinct policy approaches are a set of assumptions about the nature of educational inequalities, how they arise and how they should be addressed, which are grounded in notions of equality of opportunity and outcome. These assumptions underlying policy texts define how particular policies and approaches to widening participation in HE are both rationalised and implemented.

The interdependence of the four HE systems (Raffe, 2013) and the influence of England's HE policies (particularly those regarding funding arrangements) over policymaking in other parts of the UK is striking (Gallacher and Raffe 2011). This means that, as Gallacher and Raffe (2011) point out, convergences in policy between the home nations are equally significant as the divergences. These convergences are not surprising given that each higher education system is operating in a global context, characterised by increasing national and international competition. HEIs within each system have therefore come under increasing pressure to compete for students, staff, research and funding (Hazelkorn 2007). This increasingly competitive landscape has been fuelled by the intensification of market-driven policies, a major driver of which has been the linking of higher education and the economy, emphasised by all four governments of the home nations (Gallacher and Raffe 2011). Given that HE is regarded as a significant driver of economic progress and development, a great deal of similarity is to be expected in their higher education policies more generally as well as widening participation policies specifically. Universities around the world, and across all four countries of the UK, are caught up in a 'competition fetish' (Naidoo 2015) which is pervasive and inescapable in many ways, which can help to explain some of their commonalities.

We recognise, therefore, that the distinctions we have identified and drawn out here are subtle and nuanced. They are not, however, insignificant. They embody particular sets of assumptions about the nature of educational inequalities which can be linked to neoliberal notions of equality of opportunity on the one hand and socially democratic ideas of equality of outcome on the other. England appears to have stronger leanings towards neoliberal ideology, reflected in the way in which flexible provision is closely aligned with the marketisation of $\mathrm{HE}$, through competition and choice. It would seem that contemporary English HE policymaking appears to embody a view of the HE system as serving a largely economic function around individual success and advancement. At the same time, the Welsh Government adopts an approach which is more strongly egalitarian, reflected in the way in which its policy texts constructs HE as inclusive and diverse. Thus, whilst Wales 
also adopts a view that HE serves an economic function, it also celebrates the social contribution of $\mathrm{HE}$ in terms of both its contribution to social justice (through equipping individuals with skills and knowledge to participate economically) but its cultural and civic contribution more generally. NI and Scotland sit somewhere between these poles, with a mix of ideological orientations underlying their policy texts. Like England, to some extent, they conceived of widening participation policy as playing a role in providing 'equality of opportunity' to enter HE, and like England, there is a strong narrative of changing the individual to fit into a conventional HE system, through raising aspirations and levels of attainment (in Scottish Highers, following conventional school-based routes into HE). Whilst neither NI nor Scotland constructs the HE system as hierarchically structured to the same extent and degree as England does, they nonetheless perceive the HE landscape in rather conventional ways, and regard widening participation policy as a matter of participation in conventional (i.e. degree) level study. On the other hand, there are also socially democratic notions of equality of outcome embedded within Scottish policies of Articulation pathways and contextualised admissions, as well as NI's approach to Foundation degrees. In line with other areas of social and educational policy, it is therefore challenging to lay claim that approaches to policymaking can necessarily be linked in any unified way to political ideologies, especially in any historical way. It is also difficult to ascertain what purpose HE is perceived as serving by Scottish and NI Government's, given their mixed emphases placed around individual prosperity as well as representation of diversity.

The sets of policies explored here, and the particular assumptions which underlie them, carry different kinds of risks and benefits across and within the home nations. On the one hand, assumptions that the HE system itself is misaligned to the wider population it serves may facilitate wider access to under-represented groups and result in the kind of liberatory experience of transgression talked of by hook (1994). At the same time, creating more diversity in routes to accessing HE (such as via access or Foundation courses) may serve to exacerbate hierarchies which are already deeply entrenched in the HE system UK wide (Croxford and Raffe 2015). This could contribute to strengthening the relationship between access to high-status educational credentials and graduate level employment (Chevalier and Conlon 2003). If the purpose of $\mathrm{HE}$ is to promote social mobility and address wider societal inequalities, the approach taken in England could bring greater benefits in these terms. However, given the deeply hierarchal HE system in England, it is questionable whether the creation of more equitable outcomes (in terms of employment opportunities associated with HE credentials) is, as the HE system stands, achievable. Moreover, even when high-status educational opportunities are extended to currently under-represented groups, inequalities may still persist, as the middle classes seek alternative means of sustaining their advantage in the labour market.

Acknowledgements The research reported here forms part of a wider ESRC-funded programme of work on geographies of higher education - exploring the spatial and social im/mobilities of UK students (award no. ES/ N002121/1), led by Michael Donnelly. It is a 3-year study of the geographic movements of young people across all four 'home' nations of the UK, drawing on administrative records and qualitative fieldwork across 20 locations. Further findings and publications from the project can be found here: http://www.bath.ac. uk/projects/geographies-of-higher-education-spatial-and-social-mobilities/.

Further ESRC funding must also be acknowledged for Ceryn Evans' contribution to the analysis reported here (award no. ES/K004247/1). 


\section{Appendix}

Table 1 selected policy documents

\begin{tabular}{ll}
\hline 'Home' nation & Document \\
\hline England & Higher Education: students at the heart of the system (Department for Business, \\
& Innovation and Skills 2011) \\
& Success as a knowledge economy: teaching excellence, social mobility and student \\
choice (Department for Business, Innovation and Skills 2016) \\
National strategy for access and success in HE (Department for Business, Innovation \\
and Skills 2014) \\
For Our Future: The 21st Century Strategy and Plan for HE in Wales (Welsh \\
Assembly Government 2009) \\
Policy Statement on HE (Welsh Government 2013) \\
Strategic Approach and Plan for Widening Access to HE 2010/2011 to 2012/2013 \\
(Higher Education Funding Council for Wales 2011) \\
A stronger Scotland: The Government's programme for Scotland 2015-15 (Scottish \\
Government 2015). \\
Scottish Funding Council's corporate plan 2015-2018 (Scottish Funding Council 2015) \\
A blueprint for fairness: the final report of the commission on widening access (Scottish \\
Government 2016) \\
Access to success: an integrated regional strategy for widening participation in HE \\
(Department for Employment and Learning 2012), \\
Access to success: second annual statement on widening participation in HE \\
(Department for Employment and Learning 2016)
\end{tabular}

Open Access This article is distributed under the terms of the Creative Commons Attribution 4.0 International License (http://creativecommons.org/licenses/by/4.0/), which permits unrestricted use, distribution, and reproduction in any medium, provided you give appropriate credit to the original author(s) and the source, provide a link to the Creative Commons license, and indicate if changes were made.

\section{References}

Adnett, N., \& Tlupova, D. (2008). Informed choice? The new English student funding system and widening participation. London Review of Education, 6(3), 243-254.

Bernstein, B. (1975). Class, codes and control, volume 3: towards a theory of educational transmissions. London: Routledge and Kegan Paul.

Bernstein, B. (1996). Pedagogy, symbolic control and identity. London: Taylor and Francis.

Blanden, J., \& Machin, S. (2004). Educational inequality and the expansion of UK HE. Scottish Journal of Political Economy, 51(2), 230-249.

Boliver, V. (2006). Social inequalities of access to higher status universities in the UK: the role of university admissions decisions. In Sociology working papers 2006-7. Oxford: University of Oxford.

Brooks, R. (2013). The social construction of young people within education policy: evidence from the UK's Coalition government. Journal of Youth Studies, 16(3), 318-333.

Chevalier, A and Conlon, G. (2003). Does it pay to attend a prestigious university? Centre for the Economics of Education. London: London School of Economics and Politics.

Chowdry, H., et al. (2013). Widening participation in HE: analysis using linked administrative data. Journal of the Royal Statistical Society: Series A (Statistics in Society), 176(2), 431-457.

Croxford, L and Raffe, D. (2015). The iron law of hierarchy? Institutional differentiation in UK higher education. Studies in Higher Education, 40(9),1625-1640. 
Delamont, S and Rees, G. 1997. Understanding the Welsh education system: Does Wales need a separate 'policy sociology? Working Paper 23 Department of Education, Cardiff University of Wales.

Department for Business, Innovation and Skills. (2011). Higher education: students at the heart of the system. London: Department for Business Innovation and Skills.

Department for Business, Innovation and Skills. (2014). National strategy for access and success in higher education. London: Department for Business, Innovation and Skills.

Department for Business, Innovation and Skills. (2016). Success as a knowledge economy: Teaching excellence, social mobility and student choice. London: Department for Business, Innovation and Skills.

Department for Employment and Learning. (2012). Access to success: an integrated regional strategy for widening participation in HE. Belfast: Department for Employment and Learning.

Department for Employment and Learning. (2016). Access to success: annual statement on widening participation in HE. Belfast: Department for Employment and Learning.

Donnelly, M. (2016). Inequalities in higher education: applying the sociology of Basil Bernstein, Sociology, OnlineFirst, DOI: 0.1177/0038038516656326.

Felstead, A., Ashton, D., Green, F., \& Sung, J. (1994). International study of vocational education and training in the Federal Republic of Germany, France, Japan, Singapore and the United States. Leicester: University of Leicester.

Gallacher, J., \& Raffe, D. (2011). HE policy in post-devolution UK: more convergence than divergence? Journal of Education Policy, 27(4), 467-490.

Giddens, A. (1998). The Third Way: The renewal of social democracy. Cambridge: Polity Press.

Harrison, N., \& Hatt, S. (2010). 'Disadvantaged learners': who are we targeting? Understanding the targeting of widening participation activity in the United Kingdom using geo-demographic data from Southwest England. HE Quarterly, 64(1), 65-88.

Harrison, N. (2011). Have the changes introduced by the 2004 Higher Education Act made higher education admissions wider and fairer? Journal of Education Policy, 26(3), 449-468.

Hazelkorn, E. (2007). The impact of league tables and ranking systems on higher education decision making. Higher Education Management and Policy. 19(2),1682-3451.

Higher Education Funding Council for Wales. (2011). Strategic approach and plan for widening access to higher education 2010/2011 to 2012/2013. Cardiff: Higher Education Funding Council for Wales.

Higher Education Council Funding for Wales, 2013. Fee Plan Guidance 2014/15. Cardiff: Higher Education Funding Council for Wales.

Hook, B. (1994). Teaching to transgress. New York: Routledge.

Iannelli, C. (2007). Inequalities in entry to higher education: a comparison over time between Scotland and England and Wales. Higher Education Quarterly., 61(3), 306-333.

Jeffery, C. 2006. Final report of the devolution and constitutional change programme. www.devolution.ac. uk/final_report.htm (accessed January 11, 2011).

Keating, M. (2002). Devolution and public policy in the United Kingdom: divergence or convergence? In J. Adams \& P. Robinson (Eds.), Devolution in practice (pp. 3-21). London: IPPR.

Keating, M. (2005). Higher education in Scotland and England after devolution. Regional and Federal Studies, $15(4), 423-435$.

Lingard, B., \& Sellar, S. (2014). Representing for country: Scotland, PISA and new spatialities of educational governance. Scottish Educational Review, 46(1), 5-1.

Naidoo, R. (2015). The competition fetish in higher education: varieties, animators and consequences. British Journal of Sociology of Education, 37(1), 1-10.

Olssen, M., \& Peters, M. (2005). Neoliberalism, higher education and the knowledge economy: from the free market to knowledge capitalism. Journal of Education Policy, 20(3), 313-345.

Power, S. (2016). The politics of education and the misrecognition of Wales. Oxford Review of Education., 42(3), 285-298.

Raffe, D. (1998). Does learning begin at home? The use of 'home-international' comparisons in UK policy making. Journal of Education Policy, 13(5), 591-602.

Raffe, D. (2013). Was devolution the beginning of the end of the UK HE system? Perspectives: Policy and Practice in HE, 17(1), 11-16.

Rees, G. (2005). 2. Democratic Devolution and Education Policy in Wales: The Emergence of a National System? Contemporary Wales, 17(1), 28-43.

Rothblatt, S. ed. 2007. Education's abiding moral dilemma: merit and worth in the cross-Atlantic democracies, 1800-2006. Symposium Books Ltd.

Scottish Funding Council. (2015). Scottish Funding Council's corporate plan 2015-2018. Edinburgh: Scottish Funding Council.

Scottish Government. (2015). A stronger Scotland: the Government's programme for Scotland 2015-15. Edinburgh: Scottish Government. 
Scottish Government. (2016). A blueprint for fairness: the final report of the commission on widening access. Edinburgh: Scottish Government.

Scottish Government. (2017). Implementing a 'Blueprint for Fairness'-a report on progress with recommendations of the commission on widening access. Edinburgh: Scottish Government.

Welsh Assembly Government. (2009). For our future: The $21^{\text {st }}$ century HE strategy and plan for Wales. Welsh Assembly Government: Cardiff.

Welsh Government. (2013). Policy statement on HE. Cardiff: Welsh Government. 